\section{THE QUICK AND EASY ANSWER TO PAINLESS INJECTIONS}

Nobody likes injections and for many it is the main reason they do not visit a dentist.

General Medical now offer VibraJect, the practical and effective answer to painless injections. Using 'Gate Theory', it offers a convenient, cost effective and clinically effective way to eliminate the pain and fear from day to day injection procedures, helping clinicians to provide a positive experience that results in happier patients. VibraJect results in happier patients, more frequent visits and increased referrals.

Battery operated, using conventional batteries, VibraJect simply snaps on to your existing syringe and when activated causes the needle to vibrate. This mild vibration over-rides the pain signals so that the patient only experiences the vibratory sensation and not any pain. There is no need to learn any new procedure and there are no additional purchases required.

For further information please contact General Medical on 01380 734990, visit www.generalmedical.co.uk or emailinfo@generalmedical.co.uk.

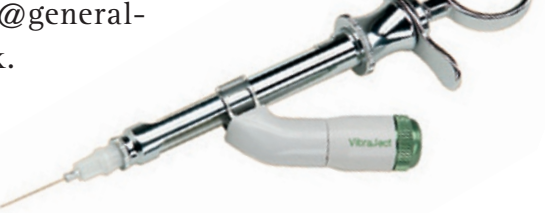

\section{TRADITIONAL IMPRESSIONS NOT NEEDED}

Traditional time consuming and often messy impressions are no longer needed when you opt for the CEREC 3D CAD/CAM System. As we all know, impressions are not always $100 \%$ accurate, which can result in costly remakes, and patients do not often enjoy the experience!

The CEREC System takes an optical impression of the preparation and the antagonist, resulting in probably the most accurate impression you will ever have taken. To allow you complete control of the finished prosthesis you specify the positions of the margins and the proximal contacts. The CEREC system goes on to swiftly fabricate the crown, inlay, onlay or veneer accurately, quickly and to the very highest quality. CEREC automatically and accurately computes the occlusal contacts referring to the antagonist to do so resulting in the perfect fit.

The CEREC 3D CAD/CAM System will help you to produce probably the best ceramic restorations possible. You will find the fit to be superb as the margin for error has been removed, the function, wear, durability and aesthetics of a CEREC prosthesis is second to none. In addition, this high-tech piece of equipment allows you to place the new prosthesis in the same visit saving you and your patient time and laboratory fees and any embarrassment at having to wear a temporary whilst waiting for the final prosthesis to be fitted.

To find out how the Sirona team can directly support your practice and for a demonstration of the CEREC 3D system contact Sirona Dental Systems Limited on 08450715040 or email: info@sironadental.co.uk. www. sironadental.co.uk.

\section{TOP CLASS ORTHODONTIC APPLIANCES}

Sparkle Dental Labs continues to produce a wide range of high quality products from the state-of-the-art dental laboratories in the UK.

With a dedicated team of orthodontic technicians, appliances are made from first class materials and crafted by highly trained, competent and indemnified experts. The team will work with you to ensure every individual case is created to exacting standards and specifications.

Furthermore, all work is manufactured in Britain with full traceability available for every product. Sparkle Dental Labs also offers free pick-up and delivery, fast turnaround times and competitive prices so you can continue offering patients a top class service with no delays.

The world-class UK laboratory complies fully with MDD and
MDR regulations. It is ISO and DAMAS accredited and offers the British Bite Mark to further guarantee the consistent quality of products and services. Sparkle Dental Labs is so confident that if you are not satisfied with the work produced, you will be offered a 100\% money back guarantee.

Contact Sparkle Dental Labs today to find out how your practice and patients can benefit by working with the best.

For more details about Sparkle Dental Labs, call 08001386255 , email customerservice@sparkledentallabs.com or visit www. sparkledentallabs.com.

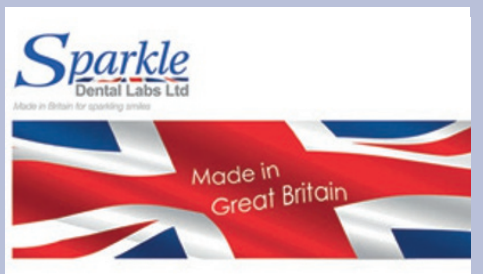

\section{DRIVING PRACTICE GROWTH}

The latest CS R4+ practice management software from Carestream Dental now features the exciting Springboard as standard, which enables you to do just this. It has been designed to focus on key areas within your practice that demonstrate your performance with regards to chair occupancy, treatment plan uptake, appointment confirmations and efficiency of recare processes, highlighting the need for improvement wherever appropriate.

All data are displayed in easy-to-read visuals, enabling any member of the team to access the results and implement changes straight away.

The practice management software also integrates seamlessly with additional programmes to further

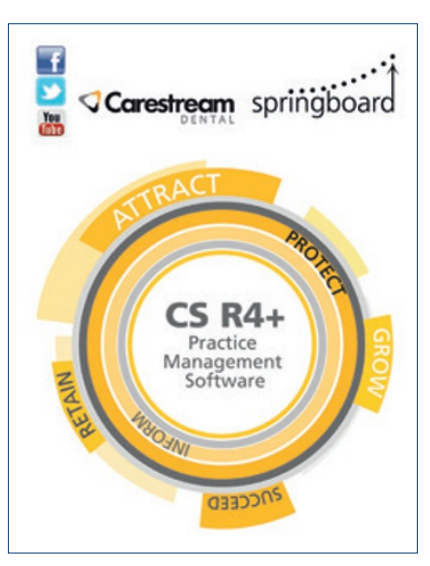
streamline your daily processes and free up precious time for staff. These include the innovative Appointmentor Online Booking System, eSignatures module, AutoPost and Text Messaging Service.

For more information, contact 0800169 9692 or visit www.carestreamdental.co.uk. 